\title{
THE FINANCIAL FRAGILITY OF FOR-PROFIT HOSPITALS: EVIDENCE FROM THE COVID-19 PANDEMIC
}

\author{
Ge Bai \\ Daniel Jiménez \\ Phillip Phan \\ Luis E. Quintero \\ Alessandro Rebucci \\ Xian Sun \\ Working Paper 29388 \\ http://www.nber.org/papers/w29388
NATIONAL BUREAU OF ECONOMIC RESEARCH
1050 Massachusetts Avenue
Cambridge, MA 02138
October 2021

We thank Maddalena Conte for excellent research assistance and the Hopkins Business of Health Initiative and the Carey Business School for financial support. We also thank New Generation Research Inc. for facilitating access to their bankruptcy data. The views expressed herein are those of the authors and do not necessarily reflect the views of the National Bureau of Economic Research.

NBER working papers are circulated for discussion and comment purposes. They have not been peer-reviewed or been subject to the review by the NBER Board of Directors that accompanies official NBER publications.

(C) 2021 by Ge Bai, Daniel Jiménez, Phillip Phan, Luis E. Quintero, Alessandro Rebucci, and Xian Sun. All rights reserved. Short sections of text, not to exceed two paragraphs, may be quoted without explicit permission provided that full credit, including $(\odot)$ notice, is given to the source. 
The Financial Fragility of For-profit Hospitals: Evidence from the COVID-19 Pandemic Ge Bai, Daniel Jiménez, Phillip Phan, Luis E. Quintero, Alessandro Rebucci, and Xian Sun NBER Working Paper No. 29388

October 2021

JEL No. G3,H51,I1,R51,Z21

\begin{abstract}
$\underline{\text { ABSTRACT }}$
We estimate the likelihood of financial distress of U.S. hospitals in 2020 due to the COVID-19 pandemic using AHA Annual Survey data for 2011-2019 and smartphone mobility data for 2020. We find that while the average likelihood of distress across all hospitals is $28.53 \%$ in 2020, slightly increasing from 2019, for-profit hospitals are much more likely to be distressed. Their average likelihood of financial distress is $39.13 \%$---a 6.93 percentage point increase from 2019. For-profit hospitals are the main providers of specialty health care services, such as psychiatric and acute long-term care, so their increased likelihood of distress poses a risk to service provision in these specialty areas, and particularly in rural communities. Our prediction model based on mobility data performs very well in sample against actual data and can potentially help policymakers and hospital administrators to monitor financial distress in real-time when case mixes change, or other large shocks materialize.
\end{abstract}

Ge Bai

The Johns Hopkins Carey Business School 100 International Drive

Baltimore, MD 21202

gbai@jhu.edu

Daniel Jiménez

International Monetary Fund

700 19th Street, N.W.,

Washington, D.C. 20431

djimenez@imf.org

Phillip Phan

The Johns Hopkins Carey Business School 100 International Drive

Baltimore, MD 21202

pphan@jhu.edu
Luis E. Quintero

The Johns Hopkins Carey Business School 100 International Drive

Baltimore, MD 21202

leq@jhu.edu

Alessandro Rebucci

The Johns Hopkins Carey Business School 100 International Drive

Baltimore, MD 21202

and NBER

arebucci@jhu.edu

Xian Sun

The Johns Hopkins Carey Business School 100 International Drive

Baltimore, MD 21202

xian.sun@jhu.edu 


\section{Introduction}

The number of hospitals that is run for-profit purposes as a share of the total has been rising significantly in the United States during and after the 2007 Great Recession. According to the annual survey of the American Hospital Association (AHA thereafter), for-profit hospitals increased from $24 \%$ of the total in 2007 to peak at $27 \%$ in 2016 (when the Federal Reserve started raising interest rates), as Figure 1 illustrates. This marked increase took place at the expense of government hospitals, while the share of non-profit hospitals held steady at $50 \%$ throughout this period. The Great Recession increased financial distress across the U.S. economy, including the hospital industry, with endowments eroded by the global decline in asset prices and government payouts under pressure from budget cuts. In the Crisis's aftermath, as the Fed flooded the U.S. capital markets of liquidity, private equity, venture capital, and other investment vehicles searching for yield expanded their footprint in the hospital industry (Wirtz, 2015). During this period, the for-profit sector of the hospital industry experienced mergers and acquisitions, product and geographic expansion to reach markets previously served by government hospitals.

The financial vulnerability of for-profit hospitals is particularly important from the policy markers' perspective. In fact, the degree to which market forces should drive the health care system continues to be hotly debated. On the one hand, market discipline ensures the efficient use of limited resources and motivates customer-oriented innovations. On the other hand, enterprises operating at the productivity frontier may not have the financial ballast to withstand natural and man-made shocks, putting consumers at risk. As we will later discuss, for-profit hospital financial fragility threatens the provision of specialty care to rural communities. More generally, individual investment decisions may not be socially optimal as they can be subject to externalities, especially if levered with cheap debt capital (Acharya et al., 2017).

In this paper, we evaluate the financial fragility of hospitals to aggregate shocks in the economy, with a focus on for-profit hospitals. We do this with a four-step empirical analysis that exploits hospital-specific smart-phone based mobility data to measure their exposures to the COVID-19 pandemic, making the analysis replicable in real-time. We show that the likelihood of finan- 
Figure 1: Hospitals By Ownership Type: 2005-2019

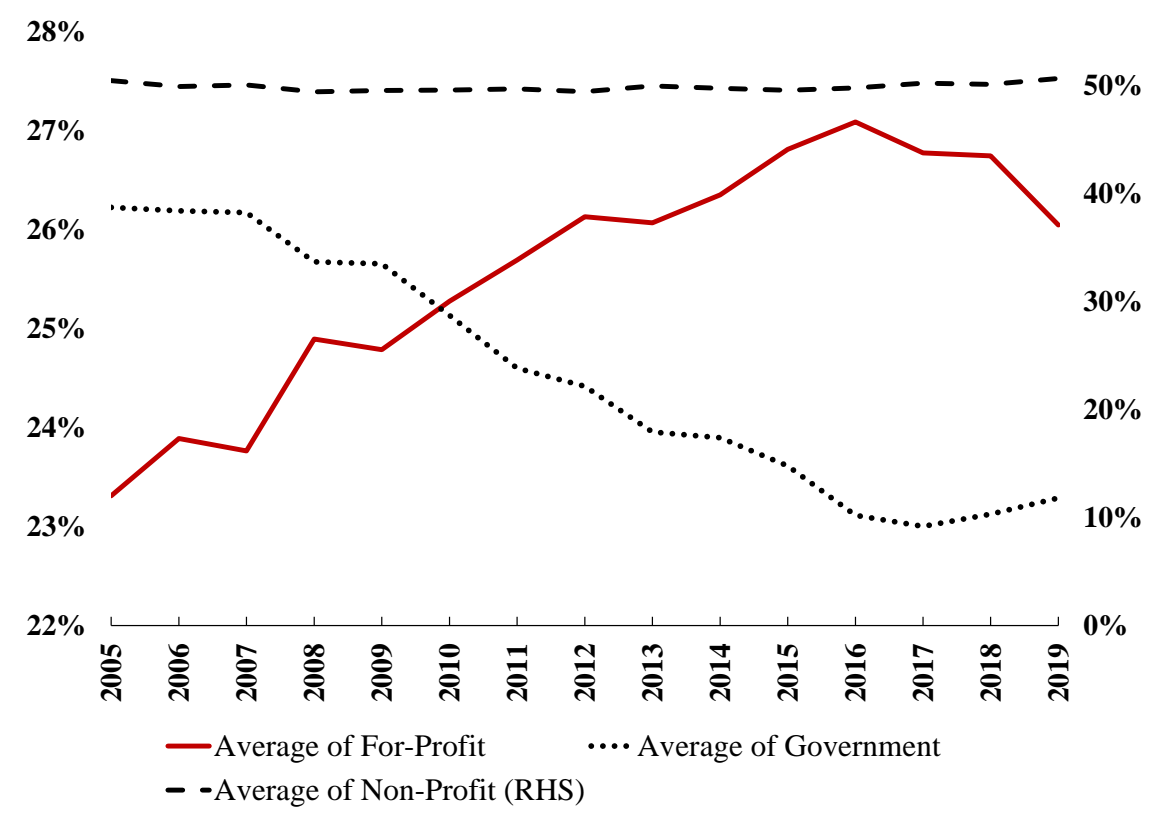

Note. The figure plots the percentage of hospitals by ownership type in the AHA Annual Survey: for-profit and government on the left scale and non-profit on the right scale.

cial distress of for-profit hospitals increased by 6.93 percentage points from $32.11 \%$ in 2019 to $39.13 \%$ in 2020 . In contrast, the estimated probability for all hospitals is $28.53 \%$ in 2020 ; only 0.44 percentage points higher than in 2019. By comparison, the likelihood of financial distress among government hospitals declined by 4.77 percentage points in 2020 . Our findings are in line with studies from other industries and also with direct evidence based on bankruptcy data. ${ }^{1}$ According to proprietary data by New Generation Inc., a market leading proprietary data provider (https://www.newgenerationresearch.com/), the number of bankruptcy filings in the whole healthcare industry was 753 in 2020, slightly higher than in 2019 but still below the 2018 peak. During the first quarter of 2021, this source shows 88 fillings in total, providing no indication of a sharp acceleration.

\footnotetext{
${ }^{1}$ Specifically, research on how bankruptcy filings initially respond to the combination of court supervised closures and worsening economic conditions find a significant drop in consumer and small business bankruptcies and a concomitant rise in large business filings that can more easily access bankruptcy protection under Chapter 11 (Wang et al., 2020). Gourinchas et al. (2020) also find that the impact of COVID-19 on business failures for small and medium sized enterprises (SMEs) is only marginally worse in 2020 compared to 2019 and note that absent government support,
} 
Further, the data on hospital operational indicators from the AHA Annual Survey that we use in our analysis reveal details that help interpreting our main results. In broad terms, inpatient surgeries and inpatient visits reduce the likelihood of distress. Other types of visits such as outpatient surgeries, outpatient visits and emergency visits increase financial distress because they are reimbursed at lower rates. In our analysis, we find that different types of hospitals load onto these operational indicators differently. For example, for-profit hospitals rely significantly more on inpatient surgeries and inpatient visits than government and non-profit hospitals. The decline in these lines of businesses due to COVID-19 in 2020, therefore, hurt them more profoundly. In contrast, government hospitals are about $50 \%$ less reliant on inpatient days than other types. Hence, the reduction in these services in 2020 may have had a lesser impact on government hospitals. According to the pre-pandemic estimates of our logit model for the prediction of hospital financial distress, government hospitals also report more ED visits than other types of hospitals. Hence, the loss of this type of business in 2020 may have helped rather than hurt their financial performance.

The financial vulnerability of for-profit hospitals potentially poses a threat to service provision. Financial distress may not only lead to eventual failure hospital, but also to the reduction of services and service quality. Our results show that specific providers such as children's orthopedic, intellectual disabilities, children's psychiatric, psychiatric, acute long-term care hospitals, and the rehabilitation, are more affected by the COVID-19 shock in 2020. For-profit hospitals are the main providers of these specialty services. For example, they represent 48 percent of psychiatric hospitals, 76 percent of acute long-term care, and 79 percent of rehabilitation hospitals.

These results are meaningful because, ex-ante, the impact of COVID-19 on hospital utilization and financial fragility is ambiguous. On the one hand, the pandemic brought about a reduction in activity because of social distancing and lock downs. In fact, elective procedures, outpatient visits, and other non-COVID-19 services declined sharply (Basu et al., 2020). On the other hand, the utilization of COVID-19 related services such as intensive care units (ICU) increased dramatically, reaching capacity in many parts of the country during 2020 citeprubinson2021intensive. Thus, whether COVID-19 helped or hurt hospital finances is an empirical question.

the failure rate of SMEs would have increased by 9.1 percentage points. 
We proceed in four steps to study how hospital finance responded to the COVID-19 pandemic. First, for each hospital in the AHA we calculate the Altman Z-score suitably modified for private corporations and identify those that experienced financial distress between 2011 and 2019. We focus on predicting hospitals' financial distress because actual bankruptcies are rare events. ${ }^{2}$ Second, we estimate a logit model that explains the financial distress variable from step 1, as a function of the operational variables typically used in the assessment of hospital credit risk and other hospital characteristics. Third, we use daily smartphone mobility data on visits to healthcare facilities to predict the operational variables in 2020. Fourth, to measure a hospital's financial exposure to the COVID-19 shock, we combine the estimated logit parameters from step 2 with the 2020 forecasted values of hospital operational indicators from step 3 to predict the probability of hospital financial distress in 2020, a period for which the operational indicators start to only become available at the end of 2021. Importantly, we analyze the results for sub-groups of hospitals, based on ownershipfor-profit, non-profit, or government-owned-because they reflect different strategic and financial priorities that will show up in their operational activities.

Our four-step approach allows us to derive a high frequency measure of hospital financial stress during the COVID-19 pandemic. As corporate financial ratios and operational indicators used to predict distress and bankruptcy are only available at quarterly or annual intervals, our approach provides real-time monitoring of financial health that economists and policy makers can use to assess the evolving impact of a major shock.

The rest of the paper is organized as follows. Section 2 places our contribution in the context of literature. Section 3 describes the data that we use and provides summary statistics. Section 4 presents the research design. Section 5 reports the empirical results. Section 6 discusses the implications of our analysis for service provision. Section 7 concludes.

\footnotetext{
${ }^{2}$ There were 655,069 firms in the healthcare industry in 2017, according to U.S. Census data. According to proprietary bankruptcy data by New Generation Inc., there were 797 bankruptcy filings in the same year, representing just $0.1 \%$ of the population.
} 


\section{$2 \quad$ Related Literature}

Although there are studies on hospital financial health during the pre-Covid period, they are limited in scope. For example, Langabeer et al. (2018) quantifies the financial distress in acute care hospitals in Texas during the 2012-2015 period using the AHA's Annual Survey Database. Holmes et al. (2017) studies the determinants of financial distress among US rural hospitals. We study all hospitals with the available financial data, covering about $90 \%$ of all hospitals in the United States.

Our paper contributes to the literature that analyzes differences in hospital performance due to their different ownership structures. In the extant literature, it is established that differences in ownership objectives and constraints result in different extents to which hospitals engage in profitenhancing activities. For example, Horwitz (2005) documents that government hospitals (for-profit hospitals) are most (least) likely to offer unprofitable services. ${ }^{3}$ Kruse and Jeurissen (2020) show that for-profit hospitals target more lucrative sectors such as elective surgeries. Silverman and Skinner (2004), Dafny (2005), and Bai and Anderson (2015) show that for-profit hospitals are more likely to engage in upcoding to increase Medicare reimbursement and set high charges to enhance revenue than non-profit hospitals. Differences in strategy related to different ownership structures may also affect service provision. Gupta et al. (2021) investigates the effects of private equity ownership on patient welfare at nursing homes. It finds that private equity ownership is associated with increases in the short-term mortality of Medicare patients and declines in other measures of patient well-being. The study also reports that there is a systematic shift in operating costs postacquisition toward non-patient care items such as monitoring fees, interest, and lease payments. We study how variation in hospital ownership affects the likelihood of financial distress in response to an aggregate shock for the universe of the U.S. hospitals and discuss potential implications for service provision. As far as we are aware, this is the first study to investigate how variations in hospital ownership relates to hospital financial performance in a systematic way.

The paper also contributes to the more narrow but growing literature on how COVID-19 affected hospitals. Mehrotra et al. (2020) find that hospitals had to close low acuity hospital beds, cancel

\footnotetext{
${ }^{3}$ In a similar vein, teaching hospitals, which are mostly non-profit or government owned, are also known to provide more uncompensated health care to the poor and uninsured (Blumenthal and Thier, 2003).
} 
elective procedures, outpatient clinic encounters, and other non-COVID-19 services. Alé-Chilet et al. (2020); Cantor et al. (2020); Ziedan et al. (2020) quantify the COVID-19 impact on the non-COVID-19 hospital activity, also using alternative high frequency data. These studies focus on service provision or certain types of activities but do not investigate the relationship between operating activities with hospital financial outcomes. Khullar et al. (2020) anticipate the financial hardship of the U.S. hospitals in mid-2020 as COVID-19 continued to spread around the nation and suggested interventions to provide support. Our paper provides an evidence-based framework to inform policy interventions to those hospitals in need.

A number of papers have looked at corporate financial distress with similar methodologies during the COVID-19 pandemic, while we focus specifically on hospitals. Carletti et al. (2020) study the impact of COVID-19 on profits and equity in a sample of Italian firms. To assess the extent to which firm solvency declined as a result of the COVID-19 shock, they calculate the Altman Z-score from the 2017-2018 fiscal years and simulate what would have happened if the 2020 COVID-19 shock had occurred in the economic milieu of 2018. They model the impact of the COVID-19 lock-down on operating revenues, labor and non-labor costs, taxes, and profits, based on the firm's exposure in the sector affected by the lock-down. Schivardi (2020) develops a method to predict which firms will become illiquid and applies it to the population of Italian limited-liability companies in order to assess the impact of emergency liquidity injections from the government.

Our paper further contributes to an emerging literature on measures of economic and financial activities using alternative, high frequency data such as smart phone-based mobility data (e.g., Chetty et al. (2020) and Couture et al. (2021)). We validate the use of such data for 2018 and 2019, the two years for which alternative and actual data are available, showing that our proposed approach works remarkably well in terms of estimated likelihood of financial measures. The proposed approach yields a real-time estimate of the typical operational variables used in the financial risk analysis of hospitals. Using daily smartphone mobility data of visits to healthcare facilities as a proxy for operational indicators can also allow us to predict financial distress earlier to support early intervention, if necessary. 


\section{Data and Summary Statistics}

We use the American Hospital Association (AHA) Annual Survey as the main source of financial and operational data on hospitals. The AHA survey reports the establishment level annual income statement, balance sheet, and operational data, which are used for the credit risk analysis of hospitals. We use data from 2011 to 2019. The sample period intentionally starts after the wave of bankruptcies triggered by Great Recession subsided. For each establishment, the main variables of interest in our analysis are inpatient surgeries, outpatient surgeries, inpatient days, emergency room visits, and outpatient visits. We also considered the share of outpatient revenue in total revenue, hospital ownership type (for-profit, non-profit or government), status as a teaching hospital, status as a rural hospital, the number of hospital beds, full-time employees, and full-time physicians, whether the hospital has airborne isolation capabilities, the number of air rooms, whether it belongs to a hospital system, and the hospital's case mix index (CMI). To parametrize the Z-score card we also used data on hospital costs reported to Medicare through the Healthcare Provider Cost Reporting Information System (HCRIS). About 5,500 hospitals have all the required financial information and operational data, with very small annuals variations in the number of observations. The AHA survey covers about $90 \%$ of all hospitals in the United States. Our hospital sample, therefore, is representative of the U.S. population. Table 6 in appendix reports summary statistics for all key variables, for all hospitals and by ownership type.

A critical variable in our analysis is the ownership type. In the AHA survey, non-profit hospitals, originally established by religious groups or philanthropists, are defined as having no shareholders. Profits must be committed to charitable, education, or other social missions (Fama and Jensen, 1983). For-profit hospitals are investor-owned and have the primary objective of maximizing to investors' return. They operate as corporations or partnerships and are not tax-exempt (Bai et al., 2021). Government-owned hospitals are owned by federal, state, or local government agencies. They face a soft budget constraint, can be subsidized and do not distribute profits. Figure 1 reports that about half hospitals in 2019 are non-profit, $20 \%$ are government-owned, and about $25 \%$ are for-profit. 
To assess a hospital's financial condition in 2020, we forecast the lower-frequency operational variables typically used in the analysis of hospital credit risk with mobile phone mobility data. Unlike statistics based on patient records, these data are available at a daily frequency and are updated every week. The data and the analysis, therefore, can be updated in real time. Chetty et al. (2020) document that mobility data are a reliable proxy for the level of aggregate and sector economic activity and can replicate the behavior of traditional indicators such as output and employment, including in health care. Couture et al. (2021) show that mobile phone mobility data are representative of U.S. movement patterns and match well conventional survey data.

Figure 2: Unique Weekly Visits to Hospital POIs

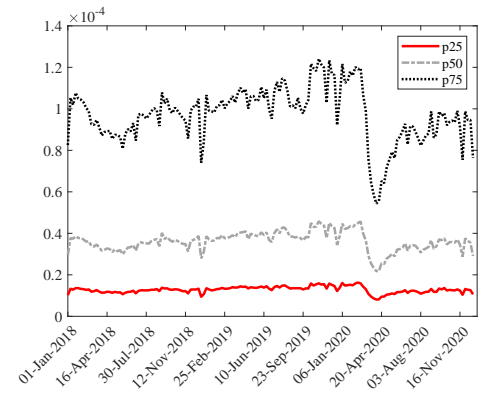

(a) Sample 1

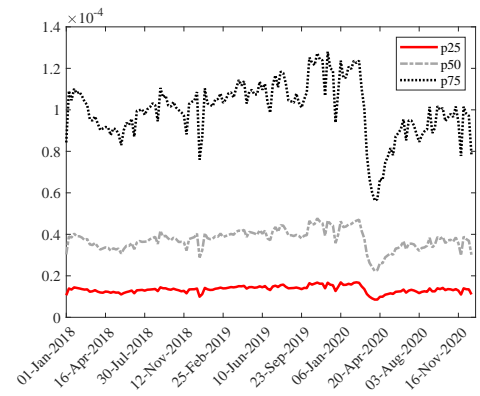

(b) Sample 2

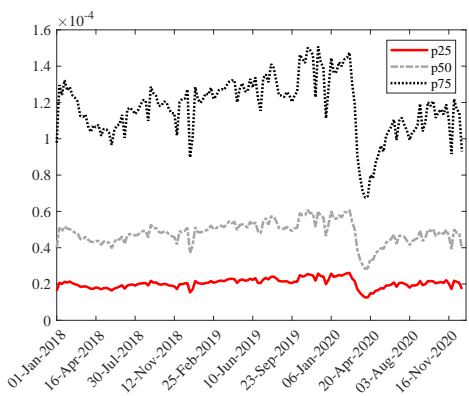

(c) Sample 3

Note. The figure shows weekly time series from January 1st 2018 to December 31st 2020, for total unique visits to hospitals POIs by distribution quartile and for of the three matched samples described in the text. Hospital-specific time series are normalized using the number of devices seen in the state each week.

We match these data at the POI-level with hospital addresses in the AHA database to construct a three matched samples of visits to hospitals, with progressively stricter definitions of a hospital visit. As we detail in appendix, the matching is accomplished by using Google places classification of all location building polygons tracked by Safegraph. Figure 2 plots the resulting weekly normalized time series, of total unique visits to hospitals by distribution quartile, from 01-Jan-2018 until 31-Dec-2020, in each of the three matched samples constructed as discussed in appendix. The figure displays flat pre-COVID-19 trend growth, suddenly interrupted by the collapse in visits in March 2020, and the subsequent protracted partial recovery. The figure also illustrates marked heterogeneity across hospitals before and after the COVID-19 shock that we exploit in our logit regression design. 


\section{Research Design}

Our empirical analysis is conducted in four steps. First, for each hospital we calculate the Altman Zscore and identify the hospitals experiencing financial distress during the 2011-2019 period. Second, we estimate a logit model that explains the financial distress binary variable constructed in the first step, as a function of operational variables typically used in the analysis of credit risk for hospitals. Third, we predict these operational variables in 2020 with high-frequency hospital-specific mobility data. Fourth, we use the estimated logit model parameters in combination with the predicted values of the hospital operational indicators to predict the probability of hospital financial distress in 2020, for which the operational indicators are only available at the end of 2021 . We now discuss each of these four steps in detail.

\subsection{Measuring and Explaining Hospitals Financial Distress}

The Altman Z-score is an indicator commonly used for predicting business failure. The original Altman Z-score (Altman, 1968) is a weighted index of five financial ratios: liquidity, profitability, leverage, solvency, and activity. The original metric was designed for public firms, but Altman (1983) re-estimated it to include public (listed) and private (unlisted) firms. Since most for-profit hospitals are unlisted corporations, we use the specification for private corporations. In this case, leverage is measured as the ratio of book value of equity to total liabilities. Another major adjustment made by Altman (1983) is to drop the turnover ratio (sales/total assets) so the index is applicable to non-manufacturing businesses. Altman et al. (2017) validates this four-factor Z-score using public and private firms in non-financial industries across all sectors in 34 countries and finds it performs well in predicting financial distress, with a classification accuracy above 90 percent.

The four-factor Z-score index we use is:

$$
Z_{i t}=6.56 A_{i t}+3.26 B_{i t}+6.72 C_{i t}+1.05 D_{i t}
$$

where $\mathrm{A}$ is working capital over total assets, B is retained earnings over total assets, $\mathrm{C}$ is earnings before interest and tax over total assets, D is book value of equity over total liabilities. We 
Figure 3: Percentage of Hospitals in Financial Distress By Ownership Type

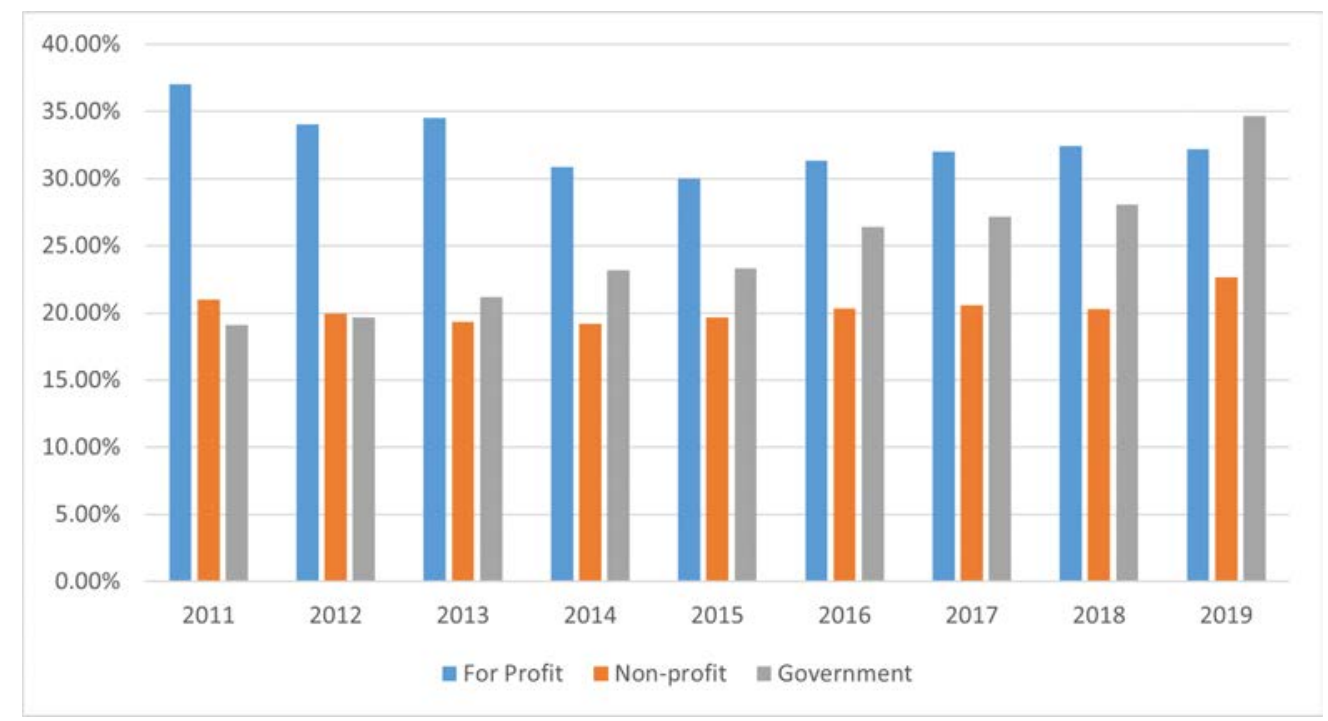

Note. The figure plots the percentage of hospitals classified as financially distressed (i.e., z-score is at or below 1.80 ) by ownership type.

compute the Z-score for each hospital in each year provided the required information is available. The coefficients next to each factor of the scorecard are validated by Altman et al. (2017). Next, following the literature, we classify as distressed $\left(Z_{i} t=1\right)$ any hospital with a Z-score value of 1.80 or lower in each period t. Figure 3 plots the results. The figure shows the share of for-profit hospitals in distress declined steadily from 2011 to 2015. Government hospitals, whose leverage has been rising during the sample period, also started to experience higher probabilities of distress since 2013. In contrast, the share of distressed non-profit hospitals holds steady throughout our sample period.

In our second step, we estimate a logit regression model to identify the operational and other characteristics predicting financial distress using data from 2011 to 2019. The specification that we estimate is

$$
\log \left(\frac{\operatorname{Distress}_{i t}}{1-\operatorname{Distress}_{i t}}\right)=\alpha+\lambda_{l}+\gamma_{s}+\theta_{t}+\sum \beta_{i} * X_{i}+\sum H_{i} * D_{j}+\epsilon_{i t}
$$

where $\alpha$ is the constant term, $\lambda_{l}$ is a county fixed effect, $\gamma_{s}$ is a service-type fixed effect, $\theta_{t}$ is a year-fixed effect, and $X_{i}$ are the five hospital operational indicators discussed above: (i) inpatient 
surgeries, (ii) outpatient surgeries, (iii) inpatient days, (iv) emergency room visits and (v) outpatient visits. $H_{i}$ is a vector of annual hospital characteristics including (a) the percent of outpatient revenues, (b) a dummy for teaching hospital, (c) a dummy for rural hospital, (d) the number of hospital beds, (e) the number of full-time employees, (f) the number of full-time physicians, (g) a dummy for airborne isolation equipped establishment, (h) the number of air rooms, (i) whether it belongs to a system or not, and (j) the CMI index when available. ${ }^{4}$

\subsection{Predicting Hospital Operational Indicators with Mobility Data}

The AHA survey releases data for selected variables toward the end of each calendar year for the previous calendar year. However, the data base is not fully updated until the first quarter of the following year. Hence, there is a long lag in the publication of information on the financial performance and operational indicators of hospitals. In this paper, we use high frequency mobility data released weekly to predict the operational indicators needed for hospitals of financial risk analysis. Specifically, we consider the following three econometric specifications to derive a stable predictive relationship between hospital mobility data and operational indicators:

$$
\begin{aligned}
& X_{i h t}=\alpha+\gamma_{c}+\beta * V_{h t}+\epsilon_{i h t} \quad \text { for } t=\{2018,2019\}, \\
& X_{i h t}=\alpha+\gamma_{c}+\theta_{h}+\beta * V_{h t}+\epsilon_{i h t} \text { for } t=\{2018,2019\} \\
& X_{i h t}=\alpha+\gamma_{c}+\beta_{1} * V_{h t}+\beta_{2} * \Delta V_{h t}+\epsilon_{i h t} \quad \text { with } \Delta V_{h t}=V_{h, t}-V_{h, t-1} \quad \text { for } \quad t=2019
\end{aligned}
$$

where $X_{i h t}$ is the operation indicator $i$ in hospital $h$ and year $t ; \alpha$ is the constant term, $\gamma_{c}$ is the state fixed effect, $\theta_{h}$ as a hospital fixed effect, $V_{h t}$ is total annual visits to hospital $h$ as tracked by mobile phone pings, and $\epsilon_{i h t}$ is the forecast error term. The first two specifications predict the level of each operational indicator using annual hospital visits only exploiting cross section variation in the data. These two regressions also pool the data for the two years for which we observe both mobility data from Safegraph and hospital operation indicators from the AHA survey (2018 and 2019). The difference between the first and the second specification is the inclusion of the hospital

\footnotetext{
${ }^{4}$ The following variables enter the regression in log-10: inpatient surgeries, outpatient surgeries, inpatient days, emergency room visits, outpatient visits, hospital beds, full-time employees, full-time physicians, and air rooms.
} 
fixed effect, $\theta_{h}$. The third specification is dynamic, and considers both the 2019 level and the change between 2019 and 2018. In all three specifications, the critical assumption is that visits to hospitals, as a proxy of business activity at these establishments, is a common factor that drives hospital performance, with different operational indicators loading differently on it.

We then use the estimated factor loadings from Equations (3)-(5), together with mobility data for 2020 to predict the value of each operational variables in $2020, \hat{X}_{i h 2020}^{p}$, where $p$ indexes the specification and sample used. We have 3 specifications from each equation above. Recalling that we have 3 matched samples as described in the data appendix, we end up with a total of at most 9 sets of estimated operational indicators per hospital as summarized and labeled in Tables 7 and 9 in appendix.

In the last step of the analysis, we predict financial distress in 2020. As we explain in detail in appendix, this step uses the estimated coefficients of the logit model 2 (one per hospital), evaluating

the hospital-specific operational indicators at their predicted values for 2020, $\hat{X}_{i h 2020}^{p}$ (at most nine per hospital). So, for each hospital, we obtain at most nine estimated likelihood of distress, depending on the matched sample to which the hospital belong. We than take the average of the predicted probability of distress across the matched samples and specifications to which the hospital record belong as our final hospital-specific outcome. The results that we report are robust to calculating these averages conditioning on the narrowest or the broadest of the three matched samples. Finally, we aggregate results by averaging again across all hopitals in the sample and by ownership type. Importantly, the model validation results that we report in the paper appendix show that our procedure predicts remarkably well in sample against 2018 and 2019 actual data from the AHA Annual Survey.

\section{$5 \quad$ Estimation Results}

In this section, we report the main empirical results. We first discuss results from the logit analysis of the predictors of financial distress in normal times. We then present results on the likelihood of running into financial distress in 2020, focusing on the vulnerability of hospitals that differ by ownership type in response to the COVID-19 shock. 


\subsection{Hospital Financial Distress in Normal Times}

Using data from the AHA Annual Survey from 2011 to 2019, for all hospitals for which have all the necessary data, we run a logit analysis of the predictors of financial distress. Table 1 reports the results. The dependent variable is the binary indicator of financial distress that we discussed above. All specifications control for year fixed effects, the service type fixed effect (whether it is a general hospital or a specialty hospital), and the state fixed effects, except that model 2 excludes year fixed effects.

The specification in column 1 of Table 1 shows that both for-profit and government hospitals experience significantly higher financial distress than non-profit hospitals, the omitted category in the regression. The coefficients of for-profit and government hospitals are 0.363 and 0.176 , respectively $(p<0.01)$. The predictive power of the ownership type survives after we include operational indicators and all other control variables as in columns (2) and (3), which also include time-fixed effects. ${ }^{5}$ The logit analysis, therefore, suggests that for-profit hospitals are at greater risk of financial distress than other hospitals in the sample. Government hospitals are also positively and significantly associated with higher financial distress, after controlling for other explanatory variables, albeit much less so than for-profit hospitals, with an estimated coefficient about half the size of for-profit hospitals.

The result is intuitive and important. It is well understood that for-profit hospitals are more profitable than non-profit and government hospitals. For example, Panel A of Figure 4 clearly illustrates this fact, and Bai and Anderson (2015) recently dissected it further. Panel B, however, shows that for-profit hospitals also experience higher earnings volatility. Higher earnings volatility, in turn, means that operating cash flow shortfalls are more likely in the face of negative shocks, possibly leading to a higher probability of financial distress as our logit analysis documents. Indeed, firms with higher cash flow volatility typically bear a higher cost of debt as measured by bond yield spreads (Minton and Schrand (1999) and Douglas et al. (2016)). In other words, the higher profitability of for-profit hospitals is no free lunch.

\footnotetext{
${ }^{5}$ In an unreported regression, we try to add the case mix index. The CMI increases the overall explanatory power of the model, but the variable is available only for a much smaller number of hospitals.
} 
Table 1: Logit Modeling of Hospital Financial Distress

\begin{tabular}{lccc}
\hline Variables & $\mathbf{( 1 )}$ & $\mathbf{( 2 )}$ & $(\mathbf{3})$ \\
\hline For-Profit & $0.612^{* * *}$ & $0.363^{* * *}$ & $0.363^{* * *}$ \\
& $(20.26)$ & $(11.10)$ & $(11.09)$ \\
Government & $0.256^{* * *}$ & $0.176^{* * *}$ & $0.176^{* * *}$ \\
& $(8.28)$ & $(5.06)$ & $(5.05)$ \\
Inpatient surgeries & & $-0.0556^{* *}$ & $-0.0571^{* *}$ \\
& & $(-2.18)$ & $(-2.24)$ \\
Outpatient surgeries & & $0.0511^{* *}$ & $0.0516^{* *}$ \\
& & $(2.31)$ & $(2.33)$ \\
Inpatient days & & $-0.444^{* * *}$ & $-0.441^{* * *}$ \\
& & $(-7.61)$ & $(-7.58)$ \\
Emergency room visits & & $0.108^{* * *}$ & $0.105^{* * *}$ \\
& & $(5.17)$ & $(5.01)$ \\
Outpatient visits & & $0.0366^{* *}$ & $0.0398^{* *}$ \\
& & $(2.30)$ & $(2.49)$ \\
Outpatient revenues $(\%)$ & & $-1.566^{* * *}$ & $-1.623^{* * *}$ \\
& & $(-15.83)$ & $(-16.24)$ \\
Teaching & & $0.336^{* * *}$ & $0.345^{* * *}$ \\
& & $(4.73)$ & $(4.84)$ \\
Rural & & $-0.271^{* * *}$ & $-0.277^{* * *}$ \\
& & $(-7.67)$ & $(-7.82)$ \\
Hospital beds & & $0.621^{* * *}$ & $0.640^{* * *}$ \\
& & $(6.79)$ & $(7.00)$ \\
Full-time employees & & $-1.129^{* * *}$ & $-1.169^{* * *}$ \\
& & $(-14.34)$ & $(-14.73)$ \\
Full-time physicians & & $0.151^{* * *}$ & $0.166^{* * *}$ \\
Airborne isolation & & $(6.15)$ & $(6.69)$ \\
& & $-0.0690^{* *}$ & $-0.0604^{* *}$ \\
Air rooms & & $(-2.46)$ & $(-2.15)$ \\
& & $-0.00854^{* * *}$ & $-0.00877^{* * *}$ \\
System & & $(-6.17)$ & $(-6.30)$ \\
Constant & & $0.170^{* * *}$ & $0.162^{* * *}$ \\
& & $(6.21)$ & $(5.91)$ \\
Year effects & & $3.011^{* * *}$ & $3.056^{* * *}$ \\
Service type effects & & $(16.20)$ & $(16.30)$ \\
State effects & & Yes & Yes \\
Pseudo-R2 & & 49420 & Yes \\
N >chi2 & & & 0.000 \\
\hline
\end{tabular}

Note. The table reports a logit regression results for different specifications using historical annual AHA survey data from 2011 to 2019 for all hospitals with the required information available that is needed for the regression analysis. The dependent variable is a dummy taking value of one when the Z-score calculated based on Equation (1) is less than 1.80. Each column reports a different specification as in Equation (2). Column 1 predicts hospital distress only based on the hospital ownership type. Columns 2 and 3 include ownership type, operating activities, hospital resources and financial performance (outpatient revenues) variables. Note that Column 2 does not include the year fixed effects. All specifications also include a location dummy which indicates if the hospital is located in rural areas.

The result is important because hospitals are unlike any other type of business, as they supply health care services. Yet, it is also well understood that private investment decisions may not be socially optimal as they can be subject to externalities (Acharya et al., 2017). Our empirical findings, therefore, provide new evidence for the ever-present policy debate on the optimal regulation of this businesses. 


\section{Figure 4: Hospital Risk-Return Profile by Ownership Type}

Panel A: Average Return on Assets

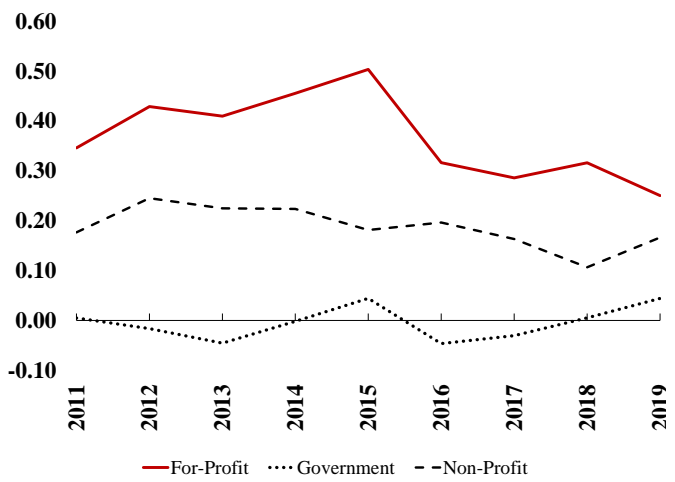

Panel B: Return on Asset Volatility

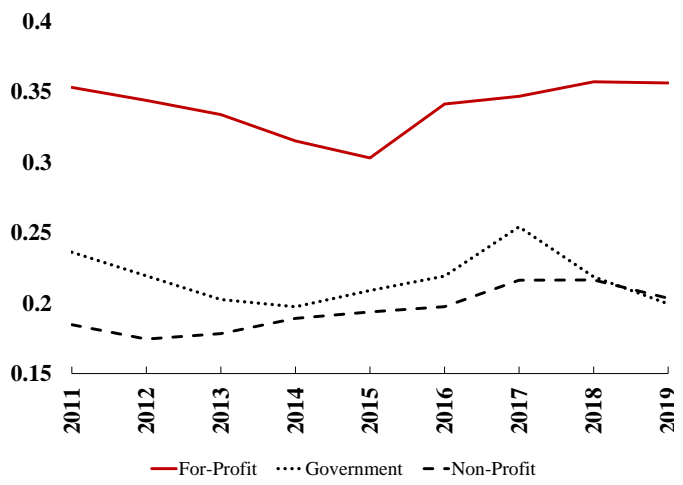

Note. The figure reports the average annual profitability and its volatility by hospital ownership during the period of 2011 to 2019. Panel A plots profitability, measured by the ratio of the operating income before interest and taxes scaled by total assets. Panel B plots the volatility of profitability among each type of hospitals in each year, measured as cross-section standard deviation without type of hospital. Source: AHA financial database.

Table 1 also shows that the five operational indicators that we include in the model are significant predictors of financial distress. The preferred specification in column 3 indicates that, after controlling for the percent of the outpatient revenues and other hospital characteristics, inpatient surgeries and inpatient days are associated with lower financial distress, while outpatient surgeries, emergency room visits, and outpatient visits are associated with higher financial distress.

The positive impact of the number of emergency room visits on hospital distress is to be expected. The Emergency Medical Treatment and Labor Act, enacted in 1986, requires emergency departments to treat anyone entering their doors, regardless of their ability to pay. This is a distinct source of costs and financial risks for hospitals and explains the positive estimated coefficient.

The reasons why we find that inpatient visits and inpatient surgeries reduce hospital financial distress, while outpatient visits and outpatient surgeries increase it, are more nuanced. Although outpatient service provision benefits patients, as it is typically priced lower than the same service offered inpatient, it poses a challenge to hospital profitability. The price tag of outpatient services, in fact, typically consists mostly of doctors' fees and procedures performed, and is much lower than 
the same service supplied inpatient. This is because hospitals add an overhead to account for much larger fixed costs associated with the inpatient stay. For example, using national data, Moses et al. (2019) report that the typical charge per outpatient visit is about $\$ 478$, compared to the charge per inpatient admission of $\$ 22,543$. Richter and Diduch (2017) show that the average for an outpatient unicompartmental knee arthroplasty procedure is $\$ 20,500$ less than the average inpatient cost of $\$ 46,845$. In this case, the source of cost difference is attributed to the facility charge, which is $\$ 3,800$ for the outpatient procedure, while it is $\$ 13,200$, or $350 \%$ more, in the impatient setting. As a result, inpatient visits and surgeries support the financial health of hospitals, while outpatient visits and surgeries do not.

The negative sign on the percent of outpatient revenue in the logit regression in Table 1 is counterintuitive. One interpretation is that if this variable has a high value, it means that the hospital business model is skewed toward outpatient services. As a consequence, there are smaller fixed costs that need to be amortized with inpatient visits. An alternative explanation is that this ratio captures the impact of technology adoption and innovation, which improves efficiency and productivity, also resulting in improved financial performance and less distress, all else equal. To see this, notice from Panel $\mathrm{C}$ of Table 6 that outpatient revenues accounts about for $51.3 \%$ of the total revenue during our sample period. According to the Deloitte Center for Health Solutions, this ratio increased steadily over time since the mid-1990s, driven by advances in clinical technology, the consumers' preferences for outpatient services due to the convenience and lower out-of-pocket cost, the pressure from Medicare, Medicaid and commercial insurance plans to shift care away from inpatient-settings, and the acquisition of physician practices to deliver outpatient care at their facilities. ${ }^{6}$

The five operational indicators that we considered are statistically and economically significant. To evaluate the economic significance of these drivers we calculate the marginal effects. As logit models are nonlinear, the estimated coefficients of interest $\hat{D}_{j}$ and $\beta_{i}$ in equation 2 reflect the impact of the covariates on the log-odds. However, here, we are interested in the partial derivatives of an individual covariate on distress itself. We calculate these marginal effects by solving for distress in

\footnotetext{
${ }^{6}$ https://www2.deloitte.com/us/en/insights/industry/health-care/outpatient-virtual-health-care-trends.
} 
equation 2 and then taking the respective partial derivative. Thus, for any operational indicators $X_{i}$, we compute

$$
\frac{\partial \text { Distress }_{i}}{\partial X_{i}}=\frac{\beta_{i} e^{\alpha+\lambda_{l}+\gamma_{s}+\theta_{t}+\sum \beta_{i} * X_{i}+\sum H_{i} * D_{j}}}{\left(1+e^{-\left(\alpha+\lambda_{l}+\gamma_{s}+\theta_{t}+\sum \beta_{i} * X_{i}+\sum H_{i} * D_{j}\right)^{2}}\right)}
$$

These partial derivatives depend on the values of all other covariates. We evaluate this expression for each observation and then average over the whole sample to obtain the reported marginal effect. Finally, as we use base-10 logarithms to transform our operational variables when estimating the logit model in equation 2 , we transform the effect of the logged variable back into levels. This gives us the marginal effects in the same unit of measure of the covariate level.

The calculations based on the preferred specification of Table 1, column 3, show that increasing inpatient surgeries by 100 in a year (about 5\% of the 1,595 mean) reduces distress probability by $2 \%$. Increasing inpatient days by 2000 (about $5 \%$ of the mean or 36,995 ) reduces distress probability by $3 \%$. In contrast, increasing emergency room visits, and outpatient visits by about $5 \%$, increases expected financial distress by $5 \%$ and $2.5 \%$, respectively. We also find that the share of outpatient revenue helps to reduce financial distress. An increase of 5 percentage points (mean of $50 \%$ ) in the share of outpatient revenue reduces the probability of financial distress by 1\%. Finally, outpatient surgeries increase financial distress. An increase of 150 outpatient surgeries annually or $5 \%$ of the mean or 3,019 , increases the probability of financial distress by $1.9 \%$.

As the additional results reported in appendix show, our main finding is robust when when we implement the logit analysis by splitting the hospital sample by ownership type. The results in Table 10 also shows that belonging to a hospital system reduces the likelihood of distress of forprofit hospitals, while it increases it for non-profit and government hospitals. The finding suggests that for-profit hospitals are more likely to benefit from economies of scope arising from being in a system. Table 10 in appendix also illustrates that rural hospitals are significantly less stressed than urban hospitals. We will discuss rural hospitals in more detail in section 6 .

\subsection{COVID-19 Impact on the Financial Health of Hospitals in 2020}

We now evaluate the COVID-19 impact on the financial health of hospitals in 2020, measured as the aggregate value of the probability of distress for 2020, averaged across all hospitals and 
by ownership type. Table 2 reports the results for 2018 and 2019 (based on actual data), and 2020 (based on mobility data). For 2020, the table also reports (in brackets) the average standard deviation across the sample/specification combinations.

The results show that the average probability of distress across all hospitals increased only marginally in 2020. In fact, the average likelihood of financial distress is $28.53 \%$ for the full sample, only slightly up from $28.09 \%$ in 2019 . The finding is in line with direct evidence on actual bankruptcies in the healthcare sector based on proprietary data by New Generation Inc and results in the extant literature on other sectors of the U.S. economy. Bankruptcy data show that the number of filings in the healthcare industry in 2020 is 753, a small increase from 678 in 2019, but significantly below the 2018 level of 937 . We surmise that our finding could be due government financial assistance for COVID-19 in the CARES Act (2020), as in the case of other sectors of the US economy-e.g., Wang et al. (2020) and Gourinchas et al. (2020).

Table 2: Predicted Financial Distress in 2020

\begin{tabular}{lccc}
\hline & 2018 Observed & 2019 Observed & 2020 Predicted \\
\hline All Hospitals & $25.15 \%$ & $28.09 \%$ & $\begin{array}{c}28.53 \% \\
(1.63 \%)\end{array}$ \\
\hline For-Profit & $32.44 \%$ & $32.20 \%$ & $39.13 \%$ \\
& & & $(1.40 \%)$ \\
Non-profit & $20.27 \%$ & $22.64 \%$ & $23.64 \%$ \\
& & & $(1.07 \%)$ \\
Government & $26.82 \%$ & $32.11 \%$ & $27.34 \%$ \\
& & & $(2.70 \%)$ \\
\hline
\end{tabular}

Note. The table reports the average probability of distress for all hospitals and by ownership type, for 2020, 2018 and 2019. For 2020, each hospital may have a different number of estimated distress probabilities depending on how many matched samples it belongs to. For 2020, we also calculate the standard deviation for each hospital across matched smaple-model specifications. The number in parenthesis is the average of these standard deviations across all hospitals.

When we break down the full sample by ownership type we uncover marked differences. Nonprofit hospitals' probability of distress increased only 1 percentage point, reaching $23.64 \%$ in 2020 , compared to $22.64 \%$ in 2019 and $20.27 \%$ in 2018 . The distress probability of government hospitals is even predicted to decline sharply, from $32.11 \%$ in 2019 to $27.34 \%$ in 2020 . In contrast, the distress probability of for-profit hospitals is $39.13 \%$ in 2020, a 6.93 percentage points increase from 2019 . 
The logit analysis of financial distress in normal times, from 2011 to 2019, illustrates a possible mechanism through which the ownership type affects hospital financial fragility. We saw earlier in Table 1 that hospitals' financial distress markedly increases with outpatient surgeries, outpatient visits, and emergency room visits. Thus, while hospital service supply disruptions due to the lockdowns has harmed patients' in need for non-COVID-19 medical care, it may not have hurt hospitals' financial health. Moreover, different hospitals supply different type of services. As Table 10 shows, for-profit hospitals' financial status is more sensitive to inpatient visits and inpatient surgeries, as a result, they are the ones hardest hit by the loss of this visits during the pandemic, comparing to other types of hospitals.

\section{Hospital Financial Distress and Service Provision}

The evidence in the previous section highlights a stark trade off between profitability and riskiness of for-profit hospitals. This trade off is common to all industries, but in the hospital sector the relationship may have knock-on effects on service provision. Thus far, we showed that for-profit hospitals are more vulnerable to than others, even thought, as it is well known, they are more profitable - arguably because more lean, nimble, and innovative. In this section, we discuss the possible costs in terms of service provision associated with the financial fragility that we document.

For this purpose, in Table 3, we start by breaking down our hospital sample by service code, ranking these categories by the number of hospitals in each code. The table also reports the average probability of distress in 2020 averaged by service code and the total outpatient visits in 2019 as a proxy for the number of patients served. This evidence shows that largest category of hospitals is general medical and surgical hospitals, accounting for about $78 \%$ of the total in our sample. The average likelihood of financial distress of the general hospital is predicted to be $25.17 \%$ in 2020 . Since we estimate that the overall average likelihood of hospital financial distress was $28.53 \%$ in 2020 (Table 5), the lower probability of financial distress among general hospitals implies that it is the specialty hospitals that are the hardest hit in 2020.

The most important specialties by number of hospitals in 2019 are Psychiatric, Acute long-term care, and Rehabilitation, which together account for $76.4 \%$ of all specialty hospitals in our sample. 
Table 3: Predicted Financial Distress in 2020 By Hospital Service Code

\begin{tabular}{|c|c|c|c|c|}
\hline Service type & $\begin{array}{l}\text { Service } \\
\text { code }\end{array}$ & Hospitals & $\begin{array}{l}\text { Distress } \\
\text { Prob. }\end{array}$ & $\begin{array}{l}\text { Total outpatient } \\
\text { visits received in } \\
2019\end{array}$ \\
\hline $\begin{array}{l}\text { General medical and sur- } \\
\text { gical }\end{array}$ & 10 & 3,597 & $25.17 \%$ & $590,065,101$ \\
\hline Psychiatric & 22 & 336 & $50.62 \%$ & $4,653,985$ \\
\hline $\begin{array}{l}\text { Acute long-term care } \\
\text { hospital }\end{array}$ & 80 & 237 & $49.12 \%$ & $1,044,597$ \\
\hline Rehabilitation & 46 & 191 & $32.40 \%$ & $3,465,085$ \\
\hline Surgical & 13 & 76 & $17.62 \%$ & $1,346,334$ \\
\hline Children's general & 50 & 46 & $17.20 \%$ & $18,300,958$ \\
\hline Orthopedic & 47 & 26 & $13.84 \%$ & 848,475 \\
\hline Children's psychiatric & 52 & 13 & $61.81 \%$ & 80,582 \\
\hline Heart & 42 & 13 & $14.89 \%$ & 832,068 \\
\hline Children's orthopedic & 57 & 11 & $74.19 \%$ & 193,893 \\
\hline $\begin{array}{l}\text { Other specialty treat- } \\
\text { ment }\end{array}$ & 49 & 10 & $34.22 \%$ & 443,075 \\
\hline Children's rehabilitation & 56 & 8 & $45.02 \%$ & 223,049 \\
\hline $\begin{array}{l}\text { Alcoholism and other } \\
\text { chemical dependency }\end{array}$ & 82 & 8 & $27.55 \%$ & 184,488 \\
\hline $\begin{array}{l}\text { Obstetrics and gynecol- } \\
\text { ogy }\end{array}$ & 44 & 8 & $18.38 \%$ & $1,314,318$ \\
\hline Cancer & 41 & 6 & $30.16 \%$ & 867,851 \\
\hline $\begin{array}{l}\text { Children's other spe- } \\
\text { cialty }\end{array}$ & 59 & 5 & $7.75 \%$ & 295,877 \\
\hline Intellectual disabilities & 62 & 2 & $70.64 \%$ & 0 \\
\hline $\begin{array}{l}\text { Children's chronic dis- } \\
\text { ease }\end{array}$ & 58 & 1 & $26.86 \%$ & 33,018 \\
\hline Eye, ear, nose and throat & 45 & 1 & $4.55 \%$ & 412,346 \\
\hline $\begin{array}{l}\text { Tuberculosis and other } \\
\text { respiratory diseases }\end{array}$ & 33 & 1 & $3.09 \%$ & 112,251 \\
\hline Chronic disease & 48 & 1 & $2.96 \%$ & 7,450 \\
\hline
\end{tabular}

Note. The table reports a breakdown of the hospital sample 1 by AHA service code, reporting the number of hospitals, the predicted financial distress for 2020, as well as the number of outpatient visits received in 2019 as a proxy for costumer served.

These hospitals, in turn, are estimated to experience very high probabilities of distress in 2020, averaging $50.62 \%, 49.12 \%$ and $32.40 \%$, respectively. The other specialties with high probability of distress in 2020 include Children's Psychiatric (61.81\%), Children's orthopedic (74.19\%), Children's rehabilitation (45.02\%), and Intellectual disabilities (70.64\%). 
To put these estimates in perspective, in 2019, the specialty hospitals received 34.66 million outpatient visits according to our data. If one patient visits a hospital 3 times a year on average (CDC suggests the number of visits per person is 2.78 in 2016), then the deterioration in the financial performance of the specialty hospitals can potentially affect 11.55 million patients if distress were to lead to cutbacks in less profitable service lines. ${ }^{7}$ The indirect economic impact through employment and local real estate markets could compound the direct effects on service provision (Alexander and Richards, 2021) in the case of liquidation and closure.

Unreported statistics based on our logit analysis of financial distress in normal times show that specialty hospitals experienced more distress than general ones. According to these estimates, the financial distress of specialty hospitals averaged $28.89 \%$ during the 2011-2019 period. Table 4 shows that COVID-19 worsened their prospects. In fact, we estimate that the likelihood of distress of specialty hospitals in 2020 is $41.74 \%$, significantly higher than in previous years and much higher than the $25.07 \%$ of general hospitals in 2020 .

When we look at the breakdown of the total number of general and specialty hospitals by ownership types, we find that for-profit hospitals are the main providers of specialty care, accounting for $68 \%$ of all specialized providers, while non-profit hospitals are the main suppliers of general care with a $61 \%$ share. Specifically, for-profit hospitals are the main suppliers of Psychiatric services (49 percent investor-owned), acute long-term care (83 percent investor-owned), and rehabilitation (83 percent investor-owned). The increased likelihood of distress and possible failure of these providers, therefore, poses a threat to specialty-care provision. If the heightened likelihood of distress were to lead to a reduction in service provision, or the closure of specialty care facilities, patients seeking such services would be affected even after the pandemic is over. ${ }^{8}$

The higher financial distress risk of for-profit specialty care hospitals has indirect implications for service provision in rural areas as well. When studying the determinants of hospital distress in Table 1, we showed that, in general, rural hospitals are much less vulnerable than urban hospitals. However, when we investigate the distress of rural and urban hospitals by service code and ownership

\footnotetext{
${ }^{7}$ https://www.cdc.gov/nchs/fastats/physician-visits.htm

${ }^{8}$ Note here that Long-COVID, a post-recovery syndrome associated with COVID-19, and the spike in mental health cases during the pandemic, will most likely require the types of rehabilitation and psychiatric care provided by hospitals at the greatest risk of financial distress.
} 
Table 4: Hospitals by Service Code And Ownership Type in 2020

\begin{tabular}{lcccccc}
\hline & Service codes & Hospitals & Distress Prob. & For-Profit & Non-Profit & Government \\
\hline General medical and surgical & $10 \& 50$ & 3,643 & $25.07 \%$ & $16 \%$ & $61 \%$ & $23 \%$ \\
Specialty & Other codes & 954 & $41.74 \%$ & $68 \%$ & $18 \%$ & $15 \%$ \\
\hline Psychiatric & 22 & 336 & $50.62 \%$ & $49 \%$ & $16 \%$ & $35 \%$ \\
Acute long-term care hospital & 80 & 237 & $49.12 \%$ & $83 \%$ & $14 \%$ & $3 \%$ \\
Rehabilitation & 46 & 191 & $32.40 \%$ & $83 \%$ & $15 \%$ & $2 \%$ \\
\hline
\end{tabular}

Note. The table reports the predicted probability of distress by service code and the fraction of hospitals of a given ownership type in each service code (and not the distress probability by ownership type). The table also reports the breakdown for general and specialty hospitals and the three largest specialty codes. Note here that general medical and surgical hospitals include children general hospitals.

type, we uncover a different picture. Table 5 presents the results. First, Panel A shows that, in line with the historical evidence in Table 1, the likelihood of distress of rural hospitals is only $17.89 \%$ in 2020, much lower than urban hospitals that have a 30.96\% average likelihood of distress. However, Panel $\mathrm{B}$ and $\mathrm{C}$ also report that about $93 \%$ percent of rural hospitals are either government or non-profit hospitals, and 99\% are general hospitals (including Children's general hospital).

Table 5: Rural and Urban Hospitals

\begin{tabular}{|c|c|c|c|}
\hline \multicolumn{4}{|c|}{ Panel A: Predicted Financial Distress in 2020 by Location } \\
\hline Urban & $30.69 \%$ & & \\
\hline Rural & $17.89 \%$ & & \\
\hline \multicolumn{4}{|c|}{ Panel B: By Ownership Type } \\
\hline & For-profit & Non-profit & Government \\
\hline Urban & $30.32 \%$ & $52.74 \%$ & $16.94 \%$ \\
\hline Rural & $7.14 \%$ & $53.92 \%$ & $38.93 \%$ \\
\hline \multicolumn{4}{|c|}{ Panel C: By Service Type } \\
\hline & Total & General Hospitals & Specialty \\
\hline Urban & 3,741 & $2,795(75 \%)$ & $946(25 \%)$ \\
\hline Rural & 856 & $848(99 \%)$ & $8(1 \%)$ \\
\hline
\end{tabular}

Note. The table reports the estimated percentage of hospitals in financial distress in 2020 broken down by location (Panel A), ownership type (Panel B), and service code (Panel C). General Hospitals include Children's General Hospitals.

Hence, although the COVID-19 shock did not affect rural hospitals directly, it may affect specialty care provision to rural communities. Rural patients typically travel long distances to access specialty care because our data show that most of them are general hospitals. But specialty hos- 
pitals suffer the most financial distress in 2020. As a result, rural patients are at greater risk of a loss of access to specialty care (travel further, longer waiting times, etc.), in the event that the risk of distress does materialize.

\section{Conclusions}

In this paper, we assess the financial fragility of for-profit hospitals in response to COVID-19. To predict financial distress in 2020 before actual hospital operational data became available, we proposed the use of smartphone mobility data as predictors of operational indicators. We find that the proposed approach forecasts hospital financial distress in sample very well for 2018 and 2019. We also find that for-profit hospitals are disproportionately affected by this major aggregate shock in 2020. In contrast, consistent with evidence from raw bankruptcy data for 2020 and similar studies of other sectors in the US economy, we find little change in the overall probability of hospital financial distress, despite the major shock of the COVID-19 pandemic. Since for-profit hospitals are the main providers of specialty health care services, such as psychiatric and acute long-term care, their increased financial distress can potentially result in long-term effects on the quality and quantity of specialty health care service provision. 


\section{References}

Acharya, Viral V, Lasse H Pedersen, Thomas Philippon, and Matthew Richardson, "Measuring systemic risk," The review of financial studies, 2017, 30 (1), 2-47.

Alexander, Diane and Michael Richards, "Economic Consequences of Hospital Closures," Available at SSRN 3848927, 2021.

Altman, Edward I, "Financial ratios, discriminant analysis and the prediction of corporate bankruptcy," The journal of finance, 1968, 23 (4), 589-609.

_ , "A complete guide to predicting, avoiding, and dealing with bankruptcy," Corporate Financial Distress, New York, 1983.

_, Małgorzata Iwanicz-Drozdowska, Erkki K Laitinen, and Arto Suvas, "Financial distress prediction in an international context: A review and empirical analysis of Altman's Z-score model," Journal of International Financial Management \& Accounting, 2017, 28 (2), 131-171.

Alé-Chilet, Jorge, Juan Pablo Atal, and Patricio Dominguez-Rivera, "Activity and the Incidence of Emergencies: Evidence From Daily Data at the Onset of a Pandemic," PIER Working Paper No. 20-016, 2020.

Bai, Ge and Gerard F Anderson, "Extreme markup: the fifty US hospitals with the highest charge-to-cost ratios," Health Affairs, 2015, 34 (6), 922-928.

_, Hossein Zare, Matthew D Eisenberg, Daniel Polsky, and Gerard F Anderson, “Analysis Suggests Government And Nonprofit Hospitals' Charity Care Is Not Aligned With Their Favorable Tax Treatment: Study examines government and nonprofit hospital charity care expenses compared to charity care obligations arising from the organizations' favorable tax treatment.," Health Affairs, 2021, 40 (4), 629-636.

Basu, Sanjay, Russell S Phillips, Robert Phillips, Lars E Peterson, and Bruce E Landon, "Primary Care Practice Finances In The United States Amid The COVID-19 Pandemic", 
Health Affairs, 2020, 39 (9), 1605-1614.

Blumenthal, D and SO Thier, "A shared responsibility: academic health centers and the provision of care to the poor and uninsured. A report to the Commonwealth Fund, Task Force on Academic Health Centers. April 2001," 2003.

Cantor, Jonathan H, Neeraj Sood, Dena Bravata, Megan Pera, and Christopher M Whaley, "The Impact of the COVID-19 Pandemic and Policy Response on Health Care Utilization: Evidence from County-level Medical Claims and Cellphone data," Technical Report, National Bureau of Economic Research 2020.

Carletti, Elena, Tommaso Oliviero, Marco Pagano, Loriana Pelizzon, and Marti G. Subrahmanyam, "The COVID-19 Shock and Equity Shortfall: Firm-level Evidence from Italy," Centre for Studies in Economics and Finance (CSEF) Working Papers, 2020, 566.

Chetty, Raj, John N Friedman, Nathaniel Hendren, Michael Stepner, and The Opportunity Insights Team, The economic impacts of COVID-19: Evidence from a new public database built using private sector data number w27431, National Bureau of Economic Research, 2020 .

Couture, Victor, Jonathan I. Dingel, Allison Green, Jessie Handbury, and Kevin R. Williams, "Measuring movement and social contact with smartphone data: a real-time application to COVID-19," Journal of Urban Economics, January 2021.

Dafny, Leemore S, "How do hospitals respond to price changes?," American Economic Review, 2005, 95 (5), 1525-1547.

Douglas, Alan VS, Alan G Huang, and Kenneth R Vetzal, "Cash flow volatility and corporate bond yield spreads," Review of Quantitative Finance and Accounting, 2016, 46 (2), 417-458.

Fama, Eugene F and Michael C Jensen, "Agency problems and residual claims," The journal of law and Economics, 1983, 26 (2), 327-349. 
Goolsbee, Austan and Chad Syverson, "Fear, lockdown, and diversion: Comparing drivers of pandemic economic decline 2020," Journal of public economics, 2021, 193, 104311.

Gourinchas, Pierre-Olivier, Sebnem Kalemli-Ozcan, Veronika Penciakova, and Nick Sander, "Covid-19 and SME failures," Technical Report, National Bureau of Economic Research 2020.

Gupta, Atul, Sabrina T Howell, Constantine Yannelis, and Abhinav Gupta, "Does private equity investment in healthcare benefit patients? evidence from nursing homes," Technical Report, National Bureau of Economic Research 2021.

Holmes, George M, Brystana G Kaufman, and George H Pink, "Predicting Financial Distress and Closure in Rural Hospitals," Journal of Rural Medicine, 2017.

Horwitz, Jill R, "Making profits and providing care: comparing nonprofit, for-profit, and government hospitals," Health affairs, 2005, 24 (3), 790-801.

Khullar, Dhruv, Amelia M. Bond, and William L. Schpero, "COVID-19 and the Financial Health of US Hospitals," JAMA, 2020.

Kruse, Florien Margareth and Patrick P.T. Jeurissen, "For-Profit Hospitals Out of Business? Financial Sustainability During the COVID-19 Epidemic Emergency Response," International Journal of Health and Policy Management, 2020, pp. 1-6.

Langabeer, James R., Karima H. Lalanib, Tiffany Champagne-Langabeerc, and Jeffrey R. Helton, "Predicting Financial Distress in Acute Care Hospitals," Hospital Topics, 2018, $96(3), 75-79$.

Mehrotra, A, M Chernew, D Linetsky, H Hatch, D Cutler, and EC Schneider, "The impact of the COVID-19 pandemic on outpatient visits: changing patterns of Care in the Newest COVID-19 hot spots. 2020," 2020. 
Minton, Bernadette A and Catherine Schrand, "The impact of cash flow volatility on discretionary investment and the costs of debt and equity financing," Journal of financial economics, 1999, $54(3), 423-460$.

Moses, Mark W, Paola Pedroza, Ranju Baral, Sabina Bloom, Jonathan Brown, Abby Chapin, Kelly Compton, Erika Eldrenkamp, Nancy Fullman, John Everett Mumford et al., "Funding and services needed to achieve universal health coverage: applications of global, regional, and national estimates of utilisation of outpatient visits and inpatient admissions from 1990 to 2016, and unit costs from 1995 to 2016," The Lancet Public Health, 2019, 4 (1), e49-e73.

Richter, Dustin L and David R Diduch, "Cost comparison of outpatient versus inpatient unicompartmental knee arthroplasty," Orthopaedic journal of sports medicine, 2017, 5 (3), 2325967117694352.

Schivardi, Fabiano, "A simple method to estimate firms liquidity needs during the Covid-19 crisis with an application to Italy," 2020.

Silverman, Elaine and Jonathan Skinner, "Medicare upcoding and hospital ownership," Journal of health economics, 2004, 23 (2), 369-389.

Wang, Jialan, Jeyul Yang, Benjamin Charles Iverson, and Raymond Kluender, "Bankruptcy and the COVID-19 Crisis," Available at SSRN 3690398, 2020.

Wirtz, RA, "Health care consolidation: Which way is up, and why are we going there," Minneapolis: Fedgazette, Federal Reserve Bank of Minneapolis, 2015.

Ziedan, Engy, Kosali I. Simon, and Coady Wing, "Effects of State COVID-19 Closure Policy on non-COVID-19 Health Care Utilization," NBER Working Paper No. 27621, 2020. 


\section{A Appendixes}

\section{A.1 Data Appendix}

\section{A.1.1 Summary Statistics}

Table 6 reports the descriptive statistics for all variables that we use as controls in our analysis of the probability of financial distress, for all hospitals and by ownership type.

Table 6: Summary Statistics

\begin{tabular}{|c|c|c|c|c|c|c|c|c|}
\hline \multicolumn{9}{|c|}{ Panel A: Resources } \\
\hline & \multicolumn{2}{|c|}{ All } & \multicolumn{2}{|c|}{ For-Profit } & \multicolumn{2}{|c|}{ Non-Profit } & \multicolumn{2}{|c|}{ Government } \\
\hline & Mean & SD & Mean & $\mathrm{SD}$ & Mean & SD & Mean & $\mathrm{SD}$ \\
\hline Full-time physicians & 23 & 94 & 3 & 8 & 30 & 121 & 29 & 76 \\
\hline Full-time employees & 900 & 1523 & 400 & 470 & 1190 & 1834 & 845 & 1410 \\
\hline Hospital beds & 151 & 187 & 105 & 115 & 180 & 207 & 140 & 196 \\
\hline Airborne Isolation & 0.58 & 0.49 & 0.40 & 0.49 & 0.72 & 0.45 & 0.48 & 0.50 \\
\hline Air rooms & 6.88 & 15.06 & 2.80 & 7.10 & 10.07 & 17.57 & 4.71 & 14.40 \\
\hline Teaching & $4.98 \%$ & $21.75 \%$ & $0.49 \%$ & $7.00 \%$ & $6.60 \%$ & $24.84 \%$ & $6.62 \%$ & $24.86 \%$ \\
\hline Rural & $16.41 \%$ & $37.04 \%$ & $46.77 \%$ & $21.11 \%$ & $17.05 \%$ & $37.61 \%$ & $28.47 \%$ & $45.12 \%$ \\
\hline System & $63.22 \%$ & $48.21 \%$ & $78.59 \%$ & $41.02 \%$ & $66.93 \%$ & $47.04 \%$ & $38.55 \%$ & $48.67 \%$ \\
\hline \multicolumn{9}{|c|}{ Panel B: Operating Activities } \\
\hline & \multicolumn{2}{|c|}{ All } & \multicolumn{2}{|c|}{ For-profit } & \multicolumn{2}{|c|}{ Non-Profit } & \multicolumn{2}{|c|}{ Government } \\
\hline & Mean & $\mathrm{SD}$ & Mean & $\mathrm{SD}$ & Mean & $\mathrm{SD}$ & Mean & $\mathrm{SD}$ \\
\hline Emergency Room Visit & 23310 & 32203 & 13409 & 24194 & 31875 & 35787 & 16143 & 26572 \\
\hline Outpatient Visits & 133788 & 239981 & 40046 & 60795 & 178115 & 270556 & 144722 & 266056 \\
\hline Inpatient Surgeries & 1540 & 2835 & 898 & 1810 & 2162 & 3348 & 933 & 2227 \\
\hline Outpatient Surgeries & 3084 & 4962 & 1859 & 3070 & 4252 & 5883 & 1966 & 3810 \\
\hline Total Inpatient Days & 36066 & 52029 & 22918 & 27554 & 42979 & 57077 & 36109 & 58570 \\
\hline \multicolumn{9}{|c|}{ Panel C: Financial Performance } \\
\hline & \multicolumn{2}{|c|}{ All } & \multicolumn{2}{|c|}{ For-profit } & \multicolumn{2}{|c|}{ Non-profit } & \multicolumn{2}{|c|}{ Government } \\
\hline & Mean & $\mathrm{SD}$ & Mean & $\mathrm{SD}$ & Mean & $\mathrm{SD}$ & Mean & $\mathrm{SD}$ \\
\hline Z score & 6.632 & 7.249 & 7.660 & 8.705 & 6.395 & 6.658 & 5.912 & 6.453 \\
\hline Financial distress & $24.58 \%$ & $43.06 \%$ & $32.71 \%$ & $46.92 \%$ & $20.29 \%$ & $40.22 \%$ & $24.56 \%$ & $43.05 \%$ \\
\hline Outpatient revenues (\%) & $50.95 \%$ & $26.59 \%$ & $31.71 \%$ & $28.31 \%$ & $57.26 \%$ & $20.64 \%$ & $61.15 \%$ & $24.36 \%$ \\
\hline
\end{tabular}

Note. The table reports summary statistics distinguishing by ownership type from 2011 to 2019 for AHA hospitals key variables organized in three panels: resources, operating activities and financial performance. All variables are from AHA survey, except for the Z-score and the financial distress variable that we constructed as described in section 4 below. 


\section{A.1.2 Mobility Data Source and Matching Procedure}

Our mobile phone mobility data is from SafeGraph, a well known provider. ${ }^{9}$ Tracking the devices' pings, the data identifies visits to any point of interest (POI). Visits to POIs are aggregated by category (e.g. hospitals, outpatient care facilities, restaurants, bars, schools, etc.) using Google Places classification (Goolsbee and Syverson, 2021). Safegraph provides comprehensive coverage of all areas in the US.

We match Safegraph data at the POI-level with hospital addresses in the AHA database to construct a dataset of visits to hospitals. The matching is accomplished by using Google places classification of all location building polygons tracked by Safegraph. We construct three matched samples, with increasingly stricter requirements with respect to the location types used to track visits. The first sample $(\mathrm{N}=4833)$ uses the full list of AHA hospitals, matching their addresses to building polygons and counts visits to those polygons, regardless of their classified type by Safegraph (using Google Places). This sample could include buildings whose main purpose has been classified as non-hospital POIs such as coffee shops, florists, pharmacies, etc., because they may be located in a hospital building. The rationale for this matching is that non-hospital POIs may still capture activity related to hospitals. The second sample $(\mathrm{N}=4633)$ restricts the identified visits to building polygons that are also classified by Safegraph as a medical facility (hospitals, outpatient centers, psychiatric centers and physicians offices $)$. The third sample $(N=3441)$ restricts the identified visits to building polygons classified by both the AHA and Safegraph as General Medical and Surgical Hospitals.

As we use 3 alternative predicting specifications as in Equations (3)-(5) in the text, combined with the three matched samples above, we end up with a total of at most 9 sets of estimated operational indicators per hospital. Table 7 summarizes and label the 9 possible combination. As not all hospitals belong to the three matched samples, because the matching criterion is progressively stricter, the number of observations will varies slightly from sample 1 to 3 (i.e. from S1 to S3 in the table below).

\footnotetext{
${ }^{9}$ In January 2020, these data were covering about 45 million devices, $16 \%$ of all smartphones in the United States.
} 
Table 7: Alternative samples And specificAtions

\begin{tabular}{l|ccc}
\hline \multicolumn{1}{c|}{ Specifications (P) } & \multicolumn{1}{c}{ Samples (S) } \\
& 1. Visits to all POIs & 2. Visits to Healthcare POIs & 3. Visits to General Hospital POIs \\
\hline 1. Stacked cross sectional & P1S1 & P1S2 & P1S3 \\
2. Panel with hospital fixed effects & P2S1 & P2S2 & P2S3 \\
3. Dynamic panel & P3S1 & P3S2 & P3S3 \\
\hline
\end{tabular}

Note. The table summarizes and labels the nine combinations of econometric specifications and matched samples that we consider. See section 3 for the details on the matched samples constructed.

\section{A.2 Model Validation Appendix}

In this appendix, we evaluate our smartphone-based mobility data predicting framework against using actual operational indicators data for 2018 and 2019, the two periods for which we observe both AHA Survey and mobility data. Recall that we rely on the specifications in Equations (3-5) to predict operational indicators with mobility data. As we have 3 specification, 3 matched samples and 5 operational indicators, we run 45 predicting regressions in total. The coefficient estimates and their standard errors of these regressions are not reported and are available on request. Table 8 only reports the $R^{2}$ coefficient for each combination of specification and samples, showing that the model fit varies slightly across specifications and operational indicators, but overall is consistently high; on average close or above 0.5 .

Table 8: GoOdness-OF-Fit MEASURE FOR ALternAtive PREDICTING MODELS

\begin{tabular}{|c|c|c|c|c|c|c|c|c|c|c|c|}
\hline & \multicolumn{3}{|c|}{ Specification 1} & \multicolumn{3}{|c|}{ Specification 2} & \multicolumn{3}{|c|}{ Specification 3} & \multirow[b]{2}{*}{ Average } & \multirow[b]{2}{*}{ Std. Dev. } \\
\hline & Sample 1 & Sample 2 & Sample 3 & Sample 1 & Sample 2 & Sample 3 & Sample 1 & Sample 2 & Sample 3 & & \\
\hline log(Emergency Room Visits) & 0.441 & 0.446 & 0.636 & 0.987 & 0.987 & 0.988 & 0.429 & 0.433 & 0.633 & 0.664 & 0.228 \\
\hline $\log ($ Outpatient Visits $)$ & 0.315 & 0.321 & 0.552 & 0.992 & 0.991 & 0.988 & 0.324 & 0.331 & 0.546 & 0.596 & 0.277 \\
\hline $\log ($ Inpatient Days $)$ & 0.372 & 0.384 & 0.570 & 0.991 & 0.991 & 0.992 & 0.386 & 0.396 & 0.578 & 0.629 & 0.253 \\
\hline $\log ($ Inpatient Surgeries $)$ & 0.466 & 0.474 & 0.551 & 0.981 & 0.981 & 0.981 & 0.470 & 0.478 & 0.555 & 0.660 & 0.218 \\
\hline $\log$ (Outpatient Surgeries) & 0.390 & 0.401 & 0.525 & 0.989 & 0.989 & 0.980 & 0.393 & 0.404 & 0.520 & 0.621 & 0.249 \\
\hline Percent of Outpatient Revenue & 0.138 & 0.136 & 0.419 & 0.992 & 0.992 & 0.987 & 0.185 & 0.185 & 0.440 & 0.497 & 0.345 \\
\hline
\end{tabular}

Note. The table reports the estimated $R^{2}$ for each combination of specifications and samples, for each of the predicted operational indicators considered. The last two columns of the table report the average and the standard deviation of these $R^{2}$ across row.

Table 9 reports the results of an in-sample model validation exercise. Column 1 uses the same specification as in column 3 of Table 1, but estimated using only data for 2018 and 2019. The pseudo-R2 using the actual indicators is 0.075 . This shows that the loss of fit relative to the model estimated over the full sample period is minimal, arguably because the logit model for 
Table 9: Model Validation:

Logit Analysis Using Alternative Predicting Regressions and Matched Samples

\begin{tabular}{|c|c|c|c|c|c|c|c|c|c|c|}
\hline & $\begin{array}{c}\text { Benchmark: } \\
\text { Column } 3 \\
\text { in Table } 3\end{array}$ & $\begin{array}{l}\text { Traffic } \\
\text { Model } \\
\text { P1S1 }\end{array}$ & $\begin{array}{l}\text { Traffic } \\
\text { Model } \\
\text { P2S1 }\end{array}$ & $\begin{array}{c}\text { Traffic } \\
\text { Model } \\
\text { P3S1 }\end{array}$ & $\begin{array}{c}\text { Traffic } \\
\text { Model } \\
\text { P1S2 }\end{array}$ & $\begin{array}{c}\text { Traffic } \\
\text { Model } \\
\text { P2S2 }\end{array}$ & $\begin{array}{l}\text { Traffic } \\
\text { Model } \\
\text { P3S2 }\end{array}$ & $\begin{array}{c}\text { Traffic } \\
\text { Model } \\
\text { P1S3 }\end{array}$ & $\begin{array}{c}\text { Traffic } \\
\text { Model } \\
\text { P2S3 }\end{array}$ & $\begin{array}{c}\text { Traffic } \\
\text { Model } \\
\text { P3S3 }\end{array}$ \\
\hline & (1) & $(2)$ & $(3)$ & $(4)$ & $(5)$ & (6) & (7) & (8) & (9) & (10) \\
\hline $\begin{array}{l}\text { Actual } \\
\text { Operational } \\
\text { Indicators }\end{array}$ & Yes & No & No & No & No & No & No & No & No & No \\
\hline $\begin{array}{l}\text { Mobility Pred. } \\
\text { Operational } \\
\text { Indicators }\end{array}$ & No & Yes & Yes & Yes & Yes & Yes & Yes & Yes & Yes & Yes \\
\hline $\begin{array}{l}\text { Control } \\
\text { Variables }\end{array}$ & Yes & Yes & Yes & Yes & Yes & Yes & Yes & Yes & Yes & Yes \\
\hline Pseudo R2 & 0.075 & 0.080 & 0.080 & 0.080 & 0.081 & 0.081 & 0.081 & 0.102 & 0.102 & 0.103 \\
\hline $\mathrm{P}>$ chi2 & 0 & 0 & 0 & 0 & 0 & 0 & 0 & 0 & 0 & 0 \\
\hline $\mathrm{N}$ & 10,256 & 8,196 & 8,196 & 8,196 & 7,967 & 7,967 & 7,967 & 6,183 & 6,183 & 6,183 \\
\hline
\end{tabular}

Note. The table reports the estimated pseudo- $R^{2}$ for different models. Column 1 reports results for the benchmark model in column 3 of Table 1, but estimated using only data for 2018 and 2019. Columns 2 through 10 report the pseudo- $R^{2}$ for nine models estimated using 2018 and 2019 predicted values of the operational indicators obtained using the three estimating equations 3, 4 and 5, respectively, and the three different matched samples in 3. All models include the same set of control variables as in column 3 of Table 1. P\# refers to th alternative Equations (3), (4) and (5), respectively. $S \#$ refers to the alternative samples. Models labeled by P3S\# have a lower number of observations because they include the one year lag.

financial distress identifies its coefficients mainly from cross section variation. In columns 2 to 10 , we replace the five observed operational indicators in the benchmark model with the nine mobilitypredicted counterparts and keep all other variables unchanged. Recall, once again, that we have three alternative matched samples and three specifications for the predicting regression.

The reported pseudo-R2s for these alternative models is comparable or actually higher than in the benchmark one based on actual data for all 9 cases. The finding therefore suggests that the mobility-based data predicted operational indicators work at least as well as the actual indicators for the purpose of predicting hospital financial distress.

\section{A.3 Predicting Financial Distress in 2020 with Mobility Data: Procedure De- tails and an Example}

In order to compute a hospital-specific probability of financial distress in 2020 we combine the logit model parameters estimated based on historical data from 2011 to 2019 with the predicted value of the operational indicators for 2020. Specifically, we have a set of at most nine predicted operational 
indicators per hospital for 2020 - as in appendix Tables 7 and 9 -and one set of parameters estimated from the logit model for each hospital. As a result, we have at most nine distinct estimated probabilities of distress for each hospital. Our hospital-specific estimated likelihood of distress is the average across these alternative estimates. As the three samples of matched hospitals use a progressively narrower definition, the sample size will shrinks going from the broader to the narrower matching criterion (see for instance Table 9 in appendix). However, the results reported are robust to conditioning the calculations of the model average on the narrowest or the broadest of the three matched samples.

Consider for example a government hospital data record, labeled hospital A, in our sample. Using equation 2 for all government hospitals, we obtain the constant, the state fixed effects, the service code fixed effect, and the coefficients of the specified variables as in column 5 of Table 10 in appendix:

Est. logit value of hospital $\mathrm{A}=$ constant + state fixed effect + service code fixed effect

$-0.119 *$ inpatient surgeries $+0.0001 *$ outpatient surgeries

$-0.362 *$ inpatient days $+0.211 *$ emergency room visits $-0.0543 *$ outpatient visits

$-1.738 *$ outpatient revenue $(\%)+1.118 *$ teaching $-0.056 *$ rural

$-0.160 *$ hospital beds $-0.362 *$ full-time employees $+0.184 *$ full-time physiscians

$-0.346 *$ airborne isolation $-0.00364 *$ air rooms $+0.285 *$ system,

where the constant is 3.08 , the state fixed effect is -1.28 , and the service code fixed effect is 0.49 . To compute the estimated logit value of financial distress for hospital A in 2020, we then replace the value of the five operating indicators (inpatient surgeries, outpatient surgeries, inpatient days, emergency room visits, and outpatient visits) with those predicted with mobility data for 2020 for hospital A, while keeping all the other hospital characteristic at the 2019 values.

We then convert the estimated logit value, in this example -0.384, to a probability of distress. As we explained earlier, we have at most nine alternative values of the operational indicators per hospital. So, we obtain at most nine estimated probability of financial distress for each hospital 
and we average over them. We finally convert the average logit value, in this example -0.384 , to a probability of distress. Thus, for this particular hospital record, we predicts that the likelihood or probability of financial distress (defined as a z value below 1.8) in 2020 is $40.5 \%$.

The largest sample of hospitals for which we have sufficient data to estimate the financial distress probability in 2020 is 4,597, accounting for $95 \%$ of all the hospitals with traffic and operational indicators data and $83 \%$ of all hospitals in our historical AHA database. This number is slightly lower than the number of observations in the broadest matched smaple of hospitals, which is 4833 , as some hospitals for which we can have mobility data do not have all the information necessary to compute the Z-score or the logit value.

\section{A.4 Additional Empirical Results}

To evaluate the interaction between ownership status and the individual predictors, we repeat the same logit analysis in Table 1 in the text by splitting the sample by ownership type. Table 10 reports the results. ${ }^{10}$ Inpatient days lower all hospital's likelihood of financial distress, regardless of whether we control for year fixed effects. The coefficient on inpatient days is -0.622 in column (2), much higher than the -0.362 for government hospitals and comparable to the -0.623 for non-profit hospitals. However, for-profit are the only type of hospitals that clearly experience less financial distress with more inpatient surgeries. The coefficient on this indicator in column 2 is -0.192 , significant at $1 \%$ level. In contrast, the other three operational indicators that we will use to model the COVID-19 impact in 2020 show more mixed impact across hospital type.

\footnotetext{
${ }^{10}$ Marginal effects are not reported but are available from the authors on request.
} 
Table 10: Logit Modeling of Hospital Financial Distress by Ownership Type

\begin{tabular}{|c|c|c|c|c|c|c|}
\hline Variables & (1) & $(2)$ & (3) & $(4)$ & $(5)$ & $(6)$ \\
\hline & \multicolumn{2}{|c|}{ For-Profit } & \multicolumn{2}{|c|}{ Non-profit } & \multicolumn{2}{|c|}{ Government } \\
\hline Inpatient surgeries & $\begin{array}{c}-0.165^{* * *} \\
(-3.63)\end{array}$ & $\begin{array}{c}-0.192^{* * *} \\
(-4.14)\end{array}$ & $\begin{array}{c}-0.0417 \\
(-0.98)\end{array}$ & $\begin{array}{c}-0.0356 \\
(-0.84)\end{array}$ & $\begin{array}{c}-0.119 * * \\
(-2.09)\end{array}$ & $\begin{array}{r}-0.0867 \\
(-1.52)\end{array}$ \\
\hline Outpatient surgeries & $\begin{array}{c}0.0964^{* * *} \\
(2.76)\end{array}$ & $\begin{array}{c}0.119^{* * *} \\
(3.35)\end{array}$ & $\begin{array}{c}0.0420 \\
(1.10)\end{array}$ & $\begin{array}{c}0.0399 \\
(1.04)\end{array}$ & $\begin{array}{c}-0.000509 \\
(-0.01)\end{array}$ & $\begin{array}{c}-0.0292 \\
(-0.55)\end{array}$ \\
\hline Inpatient days & $\begin{array}{c}-0.636^{* * *} \\
(-4.87)\end{array}$ & $\begin{array}{c}-0.622^{* * *} \\
(-4.74)\end{array}$ & $\begin{array}{c}-0.617^{* * *} \\
(-6.59)\end{array}$ & $\begin{array}{c}-0.623^{* * *} \\
(-6.66)\end{array}$ & $\begin{array}{c}-0.388^{* * *} \\
(-3.40)\end{array}$ & $\begin{array}{c}-0.362^{* * *} \\
(-3.19)\end{array}$ \\
\hline Emergency room visits & $\begin{array}{c}0.156^{* * *} \\
(5.60)\end{array}$ & $\begin{array}{c}0.159^{* * *} \\
(5.68)\end{array}$ & $\begin{array}{c}0.0196 \\
(0.52)\end{array}$ & $\begin{array}{c}0.0180 \\
(0.47)\end{array}$ & $\begin{array}{c}0.172^{* * *} \\
(2.60)\end{array}$ & $\begin{array}{c}0.211^{* * *} \\
(3.09)\end{array}$ \\
\hline Outpatient visits & $\begin{array}{c}0.0623^{* * *} \\
(3.17)\end{array}$ & $\begin{array}{c}0.0584^{* * *} \\
(2.97)\end{array}$ & $\begin{array}{c}0.105^{* *} \\
(2.52)\end{array}$ & $\begin{array}{c}0.109^{* * *} \\
(2.62)\end{array}$ & $\begin{array}{c}-0.0578 \\
(-1.25)\end{array}$ & $\begin{array}{c}-0.0543 \\
(-1.14)\end{array}$ \\
\hline Outpatient revenues (\%) & $\begin{array}{c}-1.074^{* * *} \\
(-6.53)\end{array}$ & $\begin{array}{c}-1.040^{* * *} \\
(-6.31)\end{array}$ & $\begin{array}{c}-2.016^{* * *} \\
(-12.68)\end{array}$ & $\begin{array}{c}-2.087^{* * *} \\
(-12.97)\end{array}$ & $\begin{array}{c}-1.738^{* * *} \\
(-7.05)\end{array}$ & $\begin{array}{c}-2.024^{* * *} \\
(-8.11)\end{array}$ \\
\hline Teaching & $\begin{array}{l}0.428 \\
(1.48)\end{array}$ & $\begin{array}{l}0.422 \\
(1.47)\end{array}$ & $\begin{array}{l}0.125 \\
(1.37)\end{array}$ & $\begin{array}{l}0.133 \\
(1.46)\end{array}$ & $\begin{array}{c}1.118^{* * *} \\
(6.55)\end{array}$ & $\begin{array}{c}1.185^{* * *} \\
(6.96)\end{array}$ \\
\hline Rural & $\begin{array}{c}-0.545^{* * *} \\
(-5.29)\end{array}$ & $\begin{array}{c}-0.562^{* * *} \\
(-5.44)\end{array}$ & $\begin{array}{c}-0.153^{* * *} \\
(-3.09)\end{array}$ & $\begin{array}{c}-0.154^{* * *} \\
(-3.10)\end{array}$ & $\begin{array}{c}-0.0557 \\
(-0.84)\end{array}$ & $\begin{array}{c}-0.0703 \\
(-1.05)\end{array}$ \\
\hline Hospital beds & $\begin{array}{c}0.781^{* * *} \\
(4.57)\end{array}$ & $\begin{array}{c}0.811^{* * *} \\
(4.72)\end{array}$ & $\begin{array}{c}0.980^{* * *} \\
(6.70)\end{array}$ & $\begin{array}{c}0.999^{* * *} \\
(6.82)\end{array}$ & $\begin{array}{l}-0.160 \\
(-0.82)\end{array}$ & $\begin{array}{l}-0.109 \\
(-0.56)\end{array}$ \\
\hline Full-time employees & $\begin{array}{c}-0.878^{* * *} \\
(-6.01)\end{array}$ & $\begin{array}{c}-0.927^{* * *} \\
(-6.31)\end{array}$ & $\begin{array}{c}-1.450^{* * *} \\
(-10.88)\end{array}$ & $\begin{array}{c}-1.490^{* * *} \\
(-11.10)\end{array}$ & $\begin{array}{c}-0.362^{* *} \\
(-2.05)\end{array}$ & $\begin{array}{c}-0.560^{* * *} \\
(-3.14)\end{array}$ \\
\hline Full-time physicians & $\begin{array}{c}0.327^{* * *} \\
(5.27)\end{array}$ & $\begin{array}{c}0.375^{* * *} \\
(5.79)\end{array}$ & $\begin{array}{c}0.150^{* * *} \\
(4.66)\end{array}$ & $\begin{array}{c}0.162^{* * *} \\
(4.98)\end{array}$ & $\begin{array}{c}0.184^{* * *} \\
(2.96)\end{array}$ & $\begin{array}{c}0.208^{* * *} \\
(3.31)\end{array}$ \\
\hline Airborne isolation & $\begin{array}{c}0.156^{* * *} \\
(2.87)\end{array}$ & $\begin{array}{c}0.161^{* * *} \\
(2.97)\end{array}$ & $\begin{array}{c}-0.143^{* * *} \\
(-3.32)\end{array}$ & $\begin{array}{c}-0.134^{* * *} \\
(-3.10)\end{array}$ & $\begin{array}{c}-0.346^{* * *} \\
(-5.41)\end{array}$ & $\begin{array}{c}-0.338^{* * *} \\
(-5.23)\end{array}$ \\
\hline Air rooms & $\begin{array}{c}-0.0253^{* * *} \\
(-5.46)\end{array}$ & $\begin{array}{c}-0.0249^{* * *} \\
(-5.39)\end{array}$ & $\begin{array}{c}-0.00813^{* * *} \\
(-4.59)\end{array}$ & $\begin{array}{c}-0.00839^{* * *} \\
(-4.70)\end{array}$ & $\begin{array}{c}-0.00364 \\
(-1.30)\end{array}$ & $\begin{array}{c}-0.00470 \\
(-1.64)\end{array}$ \\
\hline System & $\begin{array}{c}-0.269^{* * *} \\
(-4.70)\end{array}$ & $\begin{array}{c}-0.266^{* * *} \\
(-4.64)\end{array}$ & $\begin{array}{c}0.296^{* * *} \\
(7.67)\end{array}$ & $\begin{array}{c}0.285^{* * *} \\
(7.36)\end{array}$ & $\begin{array}{c}0.285^{* * *} \\
(4.37)\end{array}$ & $\begin{array}{c}0.258^{* * *} \\
(3.94)\end{array}$ \\
\hline Constant & $\begin{array}{c}3.021^{* * *} \\
(8.67)\end{array}$ & $\begin{array}{c}3.120^{* * *} \\
(8.89)\end{array}$ & $\begin{array}{c}4.054^{* * *} \\
(13.06)\end{array}$ & $\begin{array}{c}4.140^{* * *} \\
(13.22)\end{array}$ & $\begin{array}{c}3.078^{* * *} \\
(7.77)\end{array}$ & $\begin{array}{c}2.947^{* * *} \\
(7.31)\end{array}$ \\
\hline Year effects & No & Yes & No & Yes & No & Yes \\
\hline Service type effects & Yes & Yes & Yes & Yes & Yes & Yes \\
\hline State effects & Yes & Yes & Yes & Yes & Yes & Yes \\
\hline Pseudo-R2 & 0.0597 & 0.0610 & 0.0887 & 0.0893 & 0.138 & 0.148 \\
\hline $\mathrm{P}>$ chi2 & 0.000 & 0.000 & 0.000 & 0.000 & 0.000 & 0.000 \\
\hline $\mathrm{N}$ & 13743 & 13743 & 26058 & 26058 & 9503 & 9503 \\
\hline
\end{tabular}

Note. The table reports results splitting the full sample by type of ownership: For-profit, Non-profit and Government. All specifications are the same as in Table 1 now including ownership-type dummy. 